\title{
ASIGNACIONES DE COLACIÓN Y MOVILIZACIÓN: SU INCLUSIÓN O EXCLUSIÓN DE LAS BASES DE CÁLCULO DE INDEMNIZACIONES POR TÉRMINO DE CONTRATO. RESEÑA JURISPRUDENCIAL
}

\author{
EdUARDO YÁÑEZ MONJE* \\ Universidad de Chile
}

Es conocidísima la disputa interpretativa librada entre la Dirección del Trabajo y la Corte Suprema acerca de la inclusión o exclusión de las asignaciones de colación y movilización en las indemnizaciones por término de contrato, por lo tanto, no trataré de ilustrar al lector acerca de sus principales argumentos y contraargumentos, pues los presumo a estas alturas bastante conocidos, aunque de todas formas haré alusión a ellos en caso que algún estudiante lea esta reseña.

Por lo mismo, este escrito pretende ser más bien una reseña jurisprudencial, una revisión histórica de las líneas jurisprudenciales seguidas tanto por la Corte Suprema como por la Dirección del Trabajo acerca de este problema. Ello me parece de interés, no solo por la inseguridad que ha mostrado la Dirección del Trabajo en relación a la tesis que actualmente sustenta -lo que se vislumbra por aquel dictamen en que se alineó con la Corte Suprema, y el posterior dictamen, de dos semanas después, en que se muestra completamente arrepentida- sino también porque los protagonistas de este debate, sostenían tesis completamente opuestas a las que defienden hoy en día. Sí, así es, la Corte Suprema sostenía que debía incluirse, y a la Dirección del Trabajo le parecía que no.

Antes de entrar en esta revisión histórica, despejaremos el terreno aludiendo muy someramente al problema que da origen a esta disputa interpretativa. Ya contamos con el conocimiento de que la asignación de colación y movilización no constituyen remuneración, y en eso consiste la regla general en el Código del Trabajo, establecida en el artículo 41 inciso $2^{\circ}$ de este. El problema consiste en determinar si existe una supuesta regla especial en el artículo 172 del Código del Trabajo, que confiera a dicha asignaciones el carácter de remuneración, solo para los efectos consignados en dicho artículo. A saber, el mentado artículo 172 del Código del Trabajo menciona en su inciso primero que:

"[p]ara los efectos del pago de las indemnizaciones a que se refieren los artículos 168, 169, 170 y 171, la última remuneración mensual comprenderá toda cantidad que estuviere percibiendo el trabajador por la prestación de sus servicios al momento de terminar el contrato, incluidas las cotizaciones o imposiciones de previsión o seguridad social de cargo del trabajador y las regalías y especies avaluables en dinero, con exclusión de las asignación familiar legal, pagos por sobretiempo y beneficios o asignaciones que se otorguen en forma esporádica o por una sola vez al año, tales como gratificaciones y aguinaldos de navidad". 
Actualmente la Corte Suprema sostiene que la voz remuneración, que consigna el artículo 172, debe entenderse necesariamente referida al concepto general de remuneración establecida en el artículo 41 del Código del Trabajo, que define remuneración como "las contraprestaciones en dinero y las adicionales en especie avaluables en dinero que debe percibir el trabajador del empleador por causa del contrato de trabajo". Luego, complementa el artículo 41 diciendo que:

"no constituyen remuneración las asignaciones de movilización, de pérdida de caja, de desgaste de herramientas y de colación, los viáticos, las prestaciones familiares otorgadas en conformidad a la ley, la indemnización por años de servicios establecida en el artículo 163 y las demás que procede pagar al extinguirse la relación contractual ni, en general, las devoluciones de gastos en que se incurra por causa del trabajo".

De acuerdo a la Corte Suprema, es claro que al señalar el inciso segundo que la colación y la movilización no constituyen remuneración, difícilmente puede abogarse por su inclusión en las indemnizaciones por años de servicio y sustitutiva de aviso previo, las que en su regulación se aluden precisamente a la remuneración del trabajador.

Al contrario, la Dirección del Trabajo sostiene que hay en verdad un concepto especial de remuneración, pues la norma en comento indica que debe incluirse toda cantidad que estuviere percibiendo el trabajador, excluyendo únicamente los estipendios que al final del inciso primero del artículo 172 enumera. A contrario sensu, al no estar enumerada la colación y la movilización dentro de estas excepciones, no cabe sino incluirla dentro de las respectivas bases de cálculo, al constituir un estipendio periódico recibido por el trabajador.

Pero la Dirección del Trabajo no siempre mantuvo esa línea interpretativa. En los primeros dictámenes -a los que ya aludiremos- sostenía precisamente la tesis contraria. Y al revisar este historial de dictámenes y fallos el lector se dará cuenta que la Dirección del Trabajo siempre quiso formar una sola línea de interpretación con la Corte Suprema, adaptándose a lo resuelto por esta misma. Eso explica que el dictamen 2314/38, de 6 de junio de 2011, quisiera asimilar la doctrina de la Corte de Suprema, en virtud del creciente número de fallos -entre ellos varios en unificación de jurisprudencia- y pronunciarse en definitiva por la exclusión de dichas asignaciones, lo que generó reacciones de todo tipo ${ }^{1}$. Probablemente estas mismas reacciones condujeron a la Dirección del Trabajo a reconsiderar en tiempo récord la doctrina recién modificada, y calmar las aguas a través del Dictamen N²461/40, de 17 de junio de 2011.

Pero respetemos la línea del tiempo. Antiguamente la Dirección del Trabajo sostenía la tesis contraria. Mediante Dictamen No 465/12, de 23 de enero de 1995, la Dirección del Trabajo sostuvo que:

"conforme a la regla anterior [refiriéndose al artículo 172], para calcular la última remuneración mensual debe considerarse todo estipendio que tenga el carácter de

\footnotetext{
1 Ver UGARTe, José Luis, "La Novela de Matthei", comentario publicado el 9 de junio de 2011, en el "El Mostrador"; <http://www.elmostrador.cl/opinion/2011/06/09/la-novela-de-matthei/>
} 
remuneración conforme al inciso $1^{\circ}$ del artículo 40 del Código del Trabajo, siempre que sea de carácter mensual, que responda específicamente a la prestación de servicios del trabajador y que, si se trata de una remuneración consistente en un regalía o especie, se encuentre debidamente avaluada en dinero, incluyendo, finalmente, las imposiciones y cotizaciones previsionales y de seguridad social de cargo del trabajador. Luego proseguía '[E]n la especie y en lo que respecta a los beneficios de colación y movilización, contenidos en las cláusulas Décima y Décimo primera del contrato colectivo vigente, celebrado entre la referida Empresa y el sindicato de trabajadores de la misma, cabe hacer presente que dichas asignaciones no tienen el carácter de remuneración'. En consecuencia, 'no procede incluirlas dentro del concepto de última remuneración mensual a que se refiere el artículo 172 del Código del Trabajo”."

Esta doctrina ya poseía un largo historial, pues implicaba la ratificación de la interpretación contenida en dictámenes más antiguos, entre otros, dictámenes No 2879, de 12 de agosto de 1983, y No 3554, de 3 de octubre de 1983 [citados por el mismo dictamen].

Con posterioridad esta doctrina sería ratificada por el Dictamen No 4360/238, de 24 de julio de 1997, que con los mismos razonamientos llega a la misma conclusión. Sin embargo, la jurisprudencia de la Corte Suprema ya sostenía una cosa distinta, y de eso dio cuenta el siguiente dictamen que citaremos, que ante el bloque de fallos del máximo tribunal, que incluía dichas asignaciones en la base de cálculo de indemnizaciones por término de contrato, terminó por ceder ante una doctrina ya instalada, doctrina que en la Dirección del Trabajo perdura hasta hoy, salvo por el sobresalto de este año, al que aludíamos en la página anterior.

Es así como mediante Dictamen No 4466/308, de 21 de septiembre de 1998, la Dirección del Trabajo reconsidera la doctrina sentada hasta el minuto, señalando que:

"no cabe sino concluir que la base de cálculo de la indemnización legal por años de servicio y la sustitutiva del aviso previo deberá comprender toda cantidad cuya periodicidad de pago sea mensual y que no se encuentre expresamente excluida por el legislador. La conclusión anterior guarda armonía con la jurisprudencia de los Tribunales de Justicia, contenida, entre otras, en sentencia de 17.09.96 de la Excma. Corte Suprema que sostuvo que para el pago de las indemnizaciones señaladas deberá incluirse Toda cantidad pagada mensualmente al trabajador que no esté expresamente exceptuada por el artículo 172. En estas circunstancias, conforme a lo sostenido en párrafos anteriores, forzoso es concluir que para los efectos de calcular las indemnizaciones que nos ocupan procede incluir las asignaciones de movilización y colación percibidas en forma periódica".

Dicha conclusión era coherente con la jurisprudencia de los tribunales, como lo indica en la misma cita, en que, además de la sentencia de 19 de septiembre de 1996, podemos mencionar también la sentencia del 16 de agosto de 1995, también de la Corte Suprema. En dichas sentencias se interpreta el artículo 172 del Código del Trabajo, de tal manera que se indica que al no encontrarse exceptuada la colación y la movilización de su inclusión en las respectivas bases de cálculo, se debe perentoriamente incluirlas. 
Esta doctrina ha sido mantenida en forma impajaritable por la Dirección del Trabajo, pues ha sido ratificada varios años después, mediante Dictamen $\mathrm{N}^{\circ} 3011 / 55$ de 17 de julio de 2008, el cual nuevamente abrió el debate sobre su inclusión o exclusión, pues la doctrina jurisprudencial que en esta época comienza a vigorizarse, es aquella que excluye dichas asignaciones en las indemnizaciones por término de contrato.

Así, podemos citar la sentencia de la Corte Suprema Rol N 623-2005, de 16 de octubre de 2006, que señala en sus considerandos $5^{\circ}$ y $6^{\circ}$ :

"[q]ue al utilizar la norma transcrita, el término remuneración, debe recurrirse necesariamente al artículo 41 del Código del ramo, norma en la cual el legislador determina lo que debe entenderse por dicho concepto como también las asignaciones que no tienen dicho carácter, entre las cuales se encuentran aquellas que son materia de la causa [Considerando Quinto]. Que de la interpretación armónica de los preceptos legales en estudio, conforme lo previene el inciso primero del artículo 22 del Código Civil, no puede sino concluirse que para los efectos de determinar la base de cálculo de las indemnizaciones que corresponden con motivo del término de la relación laboral, los estipendios que deben formar parte de la base de cálculo, deben tener necesariamente, la naturaleza de remuneración. [Considerando Sexto]”.

Este razonamiento y esta conclusión han sido reproducidos por las siguientes sentencias de la Corte Suprema: sentencia Rol N 6037-2008, de 27 de noviembre de 2008; sentencia Rol No 7880-2008, de 05 de marzo de 2009, sentencia Rol No 5357-2009, de 03 de septiembre de 2009; sentencia Rol No 5060-2009, de 14 de octubre de 2009, sentencia Rol $\mathrm{N}^{\circ}$ 6886-2009, de 21 de diciembre de 2009, y sentencia Rol No 9603-2009, de 21 de abril de 2010 .

Sin embargo, como una golondrina que no hace verano, podemos mencionar la sentencia Rol No 8707-2010, de 22 de junio de 2011, que sorpresivamente se aparta de la doctrina vigente de la Corte Suprema. Pero se aparta sin romperla, no genera precisamente un cisma interpretativo, pues no ha logrado abandonar la doctrina jurisprudencial imperante, defendida por las siguientes sentencias dictadas en unificación de jurisprudencia: sentencia Rol No 7362-2010, de 26 de enero de 2011, y sentencia Rol No 8155-2010, de 12 de abril de 2011.

Por esta razón es que la Dirección del Trabajo claudicó y, a través del Dictamen $\mathrm{N}^{\circ}$ 2314/38 de 06 de junio de 2011, señaló:

"Por razones de buen servicio se ha estimado necesario emitir nuevo pronunciamiento acerca de la procedencia que las asignaciones de colación, de movilización, y en general, las referidas en el inciso $2^{\circ}$ del artículo 41 del Código del Trabajo, sean consideradas en la base de cálculo establecida en el artículo 172 del mismo Código, para el pago de las indemnizaciones sustitutiva del aviso previo y por años de servicio aludidas en la misma disposición legal. Ha sido motivo principal para la emisión del presente dictamen, la reciente, uniforme y reiterada jurisprudencia emanada de los Tribunales Superiores de Justicia sobre la materia, especialmente de la Corte Supre- 
ma, al conocer recursos de unificación de jurisprudencia, interpuestos en conformidad al artículo 483 del Código del Trabajo".

En virtud de ello, termina concluyendo la Dirección del Trabajo: "de conformidad a lo expuesto, disposiciones legales y jurisprudencia citadas, cúmpleme informar a Ud. que las asignaciones de colación y de movilización, como los demás estipendios contenidos en el inciso $2^{\circ}$ del artículo 41 del Código del Trabajo, bajo las condiciones señaladas en este Oficio, no deben incluirse en la base de cálculo para el pago de las indemnizaciones sustitutiva del aviso previo y de años de servicio, en aplicación de lo dispuesto en el artículo 172 del mismo Código.”

Y así parecía terminar este debate, zanjada en forma autoritativa la duda que por tantos años enfrentó a la Dirección del Trabajo y a la Corte Suprema, y deslegitimando así un sinfín de litigios judiciales que iban a producirse al mantener la duda abierta, a través de la mantención de la certeza jurídica a pesar o en consonancia con la justicia, según la opinión que tengamos al respecto. Aunque no contábamos con el sorpresivo arrepentimiento de la Dirección del Trabajo, que a través del Dictamen No 2461/40, de 17 de junio de 2011, reconsidera el dictamen anterior y recobra la vigencia de la histórica doctrina, eso sí, mediante la esperanza, ingenua o no, de que la disputa se resuelva por la vía legislativa. 